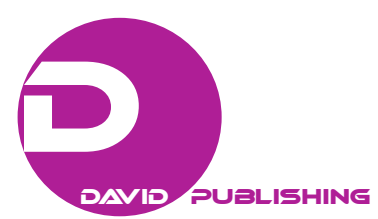

\title{
The Impact of Foreign Direct Investment on GDP Growth in East Africa
}

\author{
Worku R. Urgaia \\ Addis Ababa University, Addis Ababa, Ethiopia
}

\begin{abstract}
This study empirically investigates the impact of foreign direct investment (FDI) on GDP growth in East Africa. The study employs annual panel data, obtained from the United Nations aggregate database for the selected countries in the region over the period 1970-2015. Unlike time series and cross-sectional, panel dataset reduces the identification problems in the presence of endogenous variables and estimates more robust and efficient parameters. This study uses methods of panel autoregressive distributed lag and random effect models combined with time scaling wavelet decomposition analysis in order to show a panel of short-, medium-, and long-run effects for the entire region and individual countries. Flowing FDI into developing countries is one of the most dynamic resources which play an important role in economic development by supplementing domestic savings in capital accumulation, creating innovation and income growth, transferring modern technology and employment generation, and providing a means for creating stable and long-lasting economic growth. Examining the correlation between FDI and economic growth, cannot identify the direction of causation using traditional approaches such as dynamic panel ARDL. However, the time scaling wavelet decomposition method can help to recognize the dynamic causality in time horizons. The Granger causality of wavelet analysis in a panel indicates that there are bi-directional dynamic relationships between real GDP and FDI in the short, medium, and long run. According to the empirical evidence, the long-run estimated coefficients reveal that a one percentage increase in FDI significantly increases the real GDP by approximately 0.16 percent in a panel of seven East African countries.
\end{abstract}

Keywords: FDI, economic growth, dynamic panel ARDL, time scales wavelet decompositions

\section{Introduction}

Empirical investigation of the impact of foreign direct investment (FDI) on economic growth is essential for developed and developing economies. The inflow of FDI is a key element in providing a means for creating stable and long-lasting real GDP or economic growth OECD (2008). It improves the competitive position of a given economy, encourages the transfer of modern technology, and provides an opportunity for the host economy to promote its products more widely in international markets, positive effect on the development of international trade, and an important source for capital accumulation.

FDI is one of the most dynamic resource inflows into developing countries which can play an important

Acknowledgements: The author would like to thank his supervisors: Borje Johansson, Kristofer Mansson, and Sisay Regassa for their comments on this article which was conducted as one of the chapters of PhD dissertation.

Worku R. Urgaia, Ph.D. candidate at Addis Ababa University in collaboration with JIBS, Jonkoping University in Sweden.

Correspondence concerning this article should be addressed to Worku R. Urgaia, Department of Economics, Addis Ababa University, P.O. Box 1176, Addis Ababa, Ethiopia. 
role in economic development such as transferring modern technology and creating employment generation. It is helpful in supplementing domestic savings in capital accumulation, creating innovation and income growth. It is also used to bring integration into the global economy, enhance efficiency, and raise the skills of domestic labor as advocated by some scholars (e.g. Dupasquier \& Osakwe, 2006; Anyanwu, 2006; 2012). An increase in FDI may be associated with improving economic growth due to the inflow of capital and increase tax revenues for the host country. These make a channel of FDI into new infrastructure and other projects to boost development endeavors. Furthermore, FDI can result in the transfer of soft skills through training, availability of more advanced technology for the domestic economy and access to research and development resources (UNCTAD, 2010).

Attracting FDI has been assigned a prominent place in the strategies of economic renewal supported by policy makers at national, regional, and international levels. The experience of fast-growing East Asian and recently China, has strengthened the belief that attracting FDI is key to bridging the resource gap of the low-income countries (United Nation, 2005). This is one of the factors that make differences in economic growth across nations. As explaining growth differences across countries by Leon-Gonzalez and Vinayagathasan (2013), Koop, Leon-Gonzalez, and Strachan (2012), Leon-Gonzalez and Montolio (2012), Moral-Benito (2010; 2012), Sala-i-Martin, Doppelhofer, and Miller (2004), some countries can keep on sustainable economic growth while others cannot. The difference results from the activities of FDI that would take place in the economies. Specifically, Lee, Pesaran, and Smith (1997) consider international per capita output and its growth empirically clearly reflect the nature of steady state growth rates which differ significantly across countries.

One of the most important parameters that encourage FDI towards the economy is openness to international trade. In fact, trade liberalization enhances competition and efficiency in production allowing for technology transfer and increased TFP as Nachega and Fontaine (2006) indicate. The support for regional economic integration in Africa, in terms of trade is high among the continent's international development partners (Peter, 2010). For successful integration, various forms of measures have been taken such as lifting up of tariffs, quantitative restrictions, and exchange controls. However, Andrew (2000) points out that Africa has not embraced trade liberalization in the manner that other developing regions have. This implies that export performance in Africa over recent decades is typically found to be poor and has shown stagnation (Oliver \& Andrew, 2006). The composition of Africa's exports is essentially remained unchanged with smaller shares in the world trade. Africa will not be able to set itself on sustainable path to growth and poverty reduction, without increased trade (Economic Commission for Africa Report, 2005). Africa has generally been slow and reluctant for private sector development as a multiple effect from FDI (see Booth \& Golooba-Mutebi, 2009).

In Sub-Saharan Africa, Michalowski (2012) indicates that FDI and its effects on economic growth have risen significantly over the last three decades, though the overall performance of the region in attracting FDI seems to be disappointing. FDI inflows into Sub-Saharan Africa spread unevenly across the region with a high degree of concentration in a few countries. Although there is mixed evidence regarding the impact of FDI on economic growth in Sub-Saharan Africa, African states urgently need expanded and more dynamic private sectors, more efficient and effective infrastructure provision, and increased investment from both domestic and foreign sources (Nellis, 2005). Brixiová and Ndikumana (2011) also indicate macroeconomic policies that would help the low-income countries in Africa. East African economy has similar experiences with Sub-Saharan Africa. 
This study is proposed to make contribution to the existing knowledge by designing a new econometric model approach, time scaling wavelet decompositions in addition to the traditional dynamic panel ARDL and random effect RF methods. The purpose of this study is empirically to analyse the impact of FDI on economic growth. We review a number of related empirical studies, followed by specification of the appropriate model for estimating macroeconomic data, which inspires our study to be genuine option. The general objective is to investigate the impact of FDI on economic growth in the short, medium, and long term in East Africa. The region has been recently trying to take steps to enhance dynamic macroeconomic stabily by considering intense situations in the region and importance of stability for poverty alleviation; the associated studies conducted in this area have prime worth. This study helps to provide with tangible information about how FDI inflows are well managed and fully utilized for the base foundation of economic program implementation. Moreover, it may motivate other researchers to conduct further study on this area. It can be also used as a reference for governments' policymakers and non-governmental organizations to take some actions.

The structure of the paper begins with introduction section followed by describing an overview of existing empirical literature. The subsequent sections are intended to reveal type of data and methodology used and empirical findings with discussions. Finally, main findings of the study are summarized and concluded in the last section. The selected sample countries are Burundi, Ethiopia, Kenya, Madagascar, Malawi, Mauritius, Rwanda, Seychelles, Tanzania, Uganda, and Zambia.

\section{Review of the Related Literature}

The empirical relationship between FDI and economic growth has been given due to attention in the economic literature. Tsikata (2012) examines the relationship between the foreign exchange regime and macroeconomic performance in Eastern Africa that finds the determinant of growth, investment, and real exchange rates. Kamaludin, Sheikh, and Mohamed (2013) assess the suitability of monetary union among East African community members based on aggregate demand and aggregate supply framework with a structural vector auto-regression model to identify shocks. Such shocks are global supply, domestic supply, monetary supply, and domestic demand shocks using variance and impulse response analyses. Their results reveal that domestic demand shocks and external supply shocks are influential.

The investigation on FDI in Kenya as the main drivers for real GDP growth and those factor drivers by the findings (Abala, 2014) show that FDI is mainly market-seeking, which requires growing GDP, political stability, good infrastructure, market size as well as reduction in corruption levels. Ngeny and Mutuku (2014) explore the FDI volatility on growth in Kenya, using time series data scanning from 1970 to 2011. The results from this study suggest that FDI has a positive effect on growth whereas FDI volatility has a negative impact on growth. Notably, trade openness is not FDI inducing, thus affecting growth negatively. Basemera, Mutenyo, Hisali, and Bbaale (2012) analyse the role of institutions in determining FDI inflows to East Africa between the year 1987 and 2008. Their findings show that institutional variables, particularly economic risk and financial risk rating and corruption, have significantly influenced FDI inflows to East Africa. More specifically, the study by Brixiová and Ndikumana (2011) shows that favorable external environment, domestic factors such as reduced conflict, greater political stability, and prudent macroeconomic policies underpinned growth and structural reforms that improved the business environment of Rwanda and Ethiopia.

According to the study in Sun (2002), in this era of increasingly globalized world economy, FDI is particularly significant driving force behind the interdependence of national economies. Even though most of 
the FDI flows have concentrated on the developed countries, its importance is undeniable for developing countries as well. Aggregate wealth and total trade volumes of the developing world rise over time because, FDI flows into developing countries grow up and their participating is more than ever before in the global production network (Anyanwu, 2012). As a result, there is a positive relationship between market size and FDI inflows, openness to trade has a positive impact on FDI inflows, but increased financial activities have negative effect on FDI.

The new endogenous growth models allow that the FDI has impact on economic growth in the long run through knowledge transfers to the host country. The finding of Lund (2010) suggests that the impact of FDI on economic growth is not obviously thought. FDI may potentially influence economic growth positively but is dependent of many factors such as host country characteristics, FDI policy, and the FDI kind (Lund, 2010). A high level of economic growth attracts FDI which causes economic growth primarily in the manufacturing sector. FDI is generally seen as a composite bundle of capital stock and technology that can augment the existing stock of knowledge in the host economy through labor training, skill acquisition, and diffusion (Lund, 2010).

The FDI inflows and effects on economic growth in absolute terms in Sub-Saharan Africa according to the study by Michalowski (2012), have risen considerably over the recent three decades while the overall performance of the region in attracting FDI seems to be disappointing. FDI inflows into Sub-Saharan Africa spread unevenly across the region showing a high degree of concentration in a few countries. There is a mixed evidence regarding FDI impact on economic growth in the region such as the empirical perspectives, Anyanwu and Yameogo (2013) examine factors driving FDI inflows to African countries which have both policy and non-policy factors. These are alternatively viewed as basic economic factors, trade, and the exchange market policies. Other aspects of the investment climate as presented in Anyanwu (2012) that drives FDI to West Africa, indicating the real per capita GDP, domestic investment, trade openness, first year lag of FDI and exports, have positive and significant effect on FDI inflows.

In East Africa, however, e.g. Abala (2014) investigates that FDI in Kenya is mainly market-seeking. This requires growing GDP, political stability, good infrastructure, market size, and reduction of the level of corruption. In addition, Basemera et al. (2012) analyze the role of institutions in determining FDI inflows to East Africa between the period over 1987-2008 using fixed effect model. The findings they draw from the study show that institutional variables, particularly economic risk and financial risk rating and corruption, have significantly influenced the FDI inflows to East African region. There is also an investigation of the impact of FDI volatility on growth in Kenya using time series data scanning from the year 1970 to 2011, by applying the bound testing approach. Ngeny and Mutuku (2014) suggest that FDI has positive effect on growth whereas the FDI volatility has a negative impact on growth.

Substantial importance of the FDI to economic growth and development by complementing domestic investment, facilitating trade, and transferring knowledge and technology must be taken into account. According to OEOD (2002), to make FDI an effective integral part in the open international economic system and major catalyst to development, the primarily challenges of host countries such as the need to establish transparent, broad, and effective enabling policy environment for investment and to build the human and institutional capacities to implement should be addressed. There have been insignificant inflows of the FDI into African economies, despite the fact that Ogalo (2011) advocates FDI is fundamental to solving Africa's economic problems. However, AERC (2006) shows average annual inflows of FDI into Africa doubled in the 
1980s compared with the 1970s and it also increases remarkably in the period 2000-2003. The study in Van der Lugt, Hamblin, Burgess, and Schickerling (2011) tells us an automatic link between the FDI inflows and economic development that has been a certain notion that increased in prominence with the rise of neo-liberal thinking in the 1980s. The notion encourages the success of the so-called Asian tigers achieving high growth rates, coupled with poverty reduction through an outward market-policy orientation.

The empirical relationship between economic openness and economic performance such as income growth and export performance has been much debated in recent economic literature. However, the trade and growth relationship is not yet fully established according to the study by Rodriguez and Rodrik (2001) and Halit (2003) which demonstrates that trade liberalization does not have a straightforward relationship with growth. Pritchett (1991) also describes that there is no reliable and robust estimate of economic openness and economic performance. Thus, it is likely to be possible from cross-country data. The empirical results of Halit (2003) show that trade barriers are positively and significantly associated with growth in the developing countries. In countrary, Lloyd and MacLaren (2002) argue that fair trade has spread in developing countries as initiative aimed at lifting poor smallholder farmers out of poverty by providing them with premium prices, availability of credit, and improved community development.

On the other hand, the new growth theory argues that there is indeed a demonstrable positive relationship between economic openness and economic performance (see Edwards,1998; Srinivasan \& Bhagwati, 1999; Frankel \& Romer, 1999). The documentation of positive relationship received support from the work by Billmeier and Nannicini (2007) using matching estimators and synthetic control methods. Further developments include the construction of multi-dimensional openness indicators known as globalization indicators used by De Lombaerde and Iapadre (2008) which is another important key element. Measures of trade openness based on transformed uniform tariff equivalents derived from CGE analysis in Lloyd and MacLaren (2002) are some among others. Regarding terms of trade, the most advanced model is built on the "new open-economy macroeconomics, which synthesizes Keynesian nominal rigidities with inter-temporal approaches to open-economic dynamics, is an important effects of market structure on international trade" (Obstfeld, 2001, p. 109).

Index of openness with multi commodity-countries model as mathematical expression of the sum of a country's exports and imports to its GDP ratio has been indicated by Kotcherlakota and Sack-Rittenhouse (2000). In this review specifically, the measurement of trade openness by Lloyd and MacLaren (2002); the relationship between trade openness and economic growth by Halit (2003), and the dnamic measurement of economic openness by De Lombaerde (2009) are very crutial to be considered. The two relative prices are price of exports in terms of imports or the difference between price on commodities in foreign and domestic markets is known as terms of trade according to Obstfled and Rogoff (1996). These observations are some sources for the calculation of index of openness. Further, De Lombaerde (2009) examines empirical relationship between economic openness and economic performance. They conclude that no definitive conclusions seem to be reached yet, part of the problem being the very measurement of economic openness of a national economy. De Lombaerde (2009) proposes a new method to measure economic openness that empirically investigates the openness-growth nexus as a new tool for policy-makers.

Certain empirical studies show that there are macroeconomic effects both domestically and internationally, out of which one is the effect of wealth on consumption and other important one is the effect on investment, which are the issues of long-standing interest to economists. Cooper and Dynan (2016) suggest fluctuations in 
household wealth have driven major swings in economic activity. Individual economies in the global economy are interlinked through many different channels in a complex way which include sharing scarce resources such as oil and other commodities, political and technological developments, labor and capital movements across countries, cross-border trade in the financial assets as well as trade in goods and services. Even after allowing for such effects, there might still be residual interdependencies due to unobserved interactions and spill-over effects not taken properly into account by using the common channels of interactions (Alexander \& Pesaran, 2016).

The macroeconomic effects of large exchange rate appreciations in a sample of 128 countries (Kappler, Reisen, Schularick, \& Turkisch, 2011) show that an exchange rate appreciation has strong effects on current account balances. The empirical results of this study explicity indicate that within three years after appreciation event, the current account balance on average deteriorates by three percentage points of GDP. This effect occurs through reduction of savings without reduction in investment. Chirinos-Leañez and Pagliacci (2015) try to associate macroeconomic fluctuations and the reactions of monetary authority in order to evaluate how macroeconomics shocks affect domestic and foreign debt markets in Venezuela, where monetary policy is not the main source for macroeconomic fluctuations. The new-Keynesian macroeconomic model for the small open economy of Peru that uses Bayesian techniques and quarterly data to estimate parameters (Salas, 2010) describes that the empirical findings provide support to the weights on forward-looking components in the aggregate demand. Proano, Flaschel, Ernst, and Semmler (2006) formulate the disequilibrium aggregate supply and aggregate demand model based on sticky wages and prices and adaptive expectations concerning inflation climate in which the economy operates. Through instrumental variables in a GMM-system estimation with aggregate time series data for the U.S. and the Eurozone economies, they obtain structural parameter estimates which support the specification of theoretical model.

An observable statistical adverse impact on macro-economy caused by natural disasters has costlier events which lead to more pronounced slowdowns in production in the short run (Noy, 2009). Interestingly, developing countries face much larger output declines following the disaster of similar relative magnitude than developed countries. Furthermore, countries with higher literacy rate, better institutions, higher per capita income, and higher degree of openness to trade and higher levels of government spending are better able to withstand the initial disaster shock and prevent further spill-over. Brixiová and Ndikumana (2011), however, show that an average of 5.7 percent a year during 2001-2008, Africa has experienced the highest growth. This is due to favorable external environment, domestic factors such as reduced conflict, greater political stability and prudent macroeconomic policies underpinned growth and structural reforms that improved business environment in the countries (e.g., Rwanda and Ethiopia). The increase in trade and investment flows between Africa and China, India and the Gulf countries are becoming an important driver of growth and a buffer against shocks. The fundamental shift in macroeconomic policy thinking (Hailu \& Weeks, 2011) explains that the shift in opens space for implementing policies is to promote growth and reduce poverty in developing countries.

After carefully examining the empirical studies mentioned above in the related literature, which have brought mixed notions of FDI and economic growth relation, the study looks for the appropriate model. This new approach model can reveal the inter-temporal causal effects in different time horizons, in addition to the classical estimation between dependent and explanatory variables. We also examine whether the results of the classical estimation methods such as dynamic ARDL and RF are harmonized. 


\section{Methodology of the Study}

\section{Data Sources and Variable Descriptions}

According to the study by Lane (2001), many scholars have introduced open-economy dynamic models that incorporate imperfect competition and nominal rigidities since 1990s. A consistent framework for understanding dynamic macroeconomic models requires the key concepts in a discrete time setting and develops recursive approach in the dynamic stochastic environment. The research methodology is based on systematic use of techniques for conducting empirical research comprised of research hypotheses, methods of data selection, model specification, and variable descriptions. To this aim, the study employs annual panel data of 11 selected East African countries for the period of 1970-2015. The sources of our data are as follows: FDI net inflow in absolute term (in the current price USD) is obtained from the United Nations Conference on Trade and Development and real GDP (at 2005 constant USD), official exchange rates OER and data related to index of openness IO and terms of trade TOT are from the United Nations aggregate database. The real GDP, FDI, IO, TOT, and OER are macroeconomic variables to be used. IO and TOT are indexed by own calculations based on real GDP at constant 2005 USD, while consumption expenditure, exports, and imports are directly obtained from the sources.

In this study we employ the methodology of panel dataset because it allows us to identify certain parameters, without the need to make restrictive assumptions and produce more efficient estimation of parameters. This methodology is helpful to reduce the identification problems in the presence of endogenous variables and measurement errors. It produces much more quality outcomes in terms of robustness to omitted variables and identification of individual dynamics as compared to the time series and the cross-sectional datasets (see Verbeek, 2004; Baltagi, 2005). The selection of panel countries is based on availability of data on the series and a common economic nature in the sample study.

\section{Framework of the Models}

This section tries to specify the appropriate methods in the estimations of economic growth which are explained by FDI and other control variables. The methods we use in this study will be panel autoregressively distributed lag and random effect models combined with time scaling wavelet decomposition analysis. Reasons for choosing these kinds of models are to undertake a panel of short-, medium-, and long-run analyses for the entire region and individual countries. FDI contributes to economic growth only when a sufficient absorptive capability of the advanced technologies is available in the host economy. Some scholars argue that growth in modeling an economy with a continuum of agents is indexed by their level of ability. For instance, as a benchmark for modeling the economy, this study follows the Solow growth model specification further developed by Borensztein et al. (1998), Alfaro et al. (2000), and Carkovic and Rosse (2004).

We assume the standard panel of open macroeconomic models in the Cob-Douglas form by scaling variables in such a way that population equals unity. In addition, agents live for last one period in foreign production sector, $Y^{F D I}$. The foreign production sector is assumed to be owned entirely by foreign investors that use foreign capital and domestically supplied labor of perfectly competitive and technology of the Cobb-Douglas constant returns to scale as

$$
Y_{i t}^{F D I}=A L_{i t}^{\beta}\left(K_{i t}^{f d i}\right)^{1-\beta}
$$

where $0<\beta<1$ is the stock of foreign capital, $L_{i t}$ denotes the domestic labor, and $\mathrm{A}$ is a productivity parameter. 
The total output in the economy is mainly explained by GDP. In addition to FDI, there are also some other factors affecting domestic economic sector such as IO, TOT, and OER. With multi-commodity countries, IO can be expressed mathematically as the sum of a country's exports and imports to its GDP ratio according to the study by Kotcherlakota and Sack-Rittenhouse (2000). We take into account measures of trade openness (Lloyd \& MacLaren, 2002), trade openness and economic growth: a cross-country empirical investigation (Halit, 2003), and dynamic measurement of economic openness (De Lombaerde, 2009) which can be used as the foundation for the calculation of IO index.

The two relative prices are price of exports in terms of imports known as terms of trade TOT which are discussed by Obstfled and Rogoff (1996). We obtain terms of trade as the difference between price on commodities in foreign and domestic markets. Trade is the difference between monetary value of exports and imports of output in an economy over a certain period. Let the net export be defined as $N X_{i t} \equiv\left(\frac{1}{Y_{i t}}\right)\left(Y_{i t}-\frac{P_{i t}^{F}}{P_{i t}} C_{i t}\right)$ in terms of domestic output, expressed as a fraction of steady state output $Y$. Then the first order approximation in the form of logarithmic function as $\ln$ terms (Gali \& Monacelli, 2005) leads to

$$
\begin{gathered}
\ln \left(Y_{i t} . N X_{i t}\right) \equiv \ln \left[Y_{i t}\left(\frac{1}{Y_{i t}}\right)\left(Y_{i t}-\frac{P_{i t}^{F}}{P_{i t}^{H}} C_{i t}\right)\right]=\ln Y_{i t}-\ln \left(\frac{P_{i t}^{F}}{P_{i t}^{H}} C_{i t} . Y_{i t}\right) \\
\Rightarrow \ln Y_{i t}+\ln N X_{i t}=\ln Y_{i t}-\ln C_{i t}-\ln Y_{i t}+\ln P_{i t}^{H}-\ln P_{i t}^{F} \\
\Rightarrow \ln N \mathrm{X}_{\mathrm{it}}=-\ln \mathrm{Y}_{\mathrm{it}}-\ln \mathrm{C}_{\mathrm{it}}-\left(\mathrm{p}_{\mathrm{it}}^{\mathrm{F}}-\mathrm{p}_{\mathrm{it}}^{\mathrm{H}}\right) \Rightarrow \ln N \mathrm{X}_{\mathrm{it}}=-\ln \mathrm{Y}_{\mathrm{it}}-\ln \mathrm{C}_{\mathrm{it}}-\mathrm{TOT}_{\mathrm{it}} \\
\mathrm{TOT}_{\mathrm{it}}=-\left(\ln \mathrm{Y}_{\mathrm{it}}+\ln \mathrm{C}_{\mathrm{it}}+\ln \mathrm{ln} \mathrm{X}_{\mathrm{it}}\right)
\end{gathered}
$$

Under multi-commodity and multi-country model, TOT is the difference between the real GDP and both domestic consumption and net exports (Reinsdorf, 2010). In the process of dynamic output production if export price over import price times 100 exceeds over 100 percent, then the economy is doing net capital accumulation since more money coming in than going out from the economy (Reinsdorf, 2009).

The random effects model approach assumes that intercepts of the individuals are different and independent of explanatory variables but they can be treated as drawings from the distribution with mean and variance. Therefore, a panel of 11 East African countries' macroeconomic modeling, including TOT, can be expressed as

$$
\begin{aligned}
& \ln Y_{\text {it }}=\mathrm{f}\left(\operatorname{lnFDI}_{\mathrm{it}}, \mathrm{IO}_{\mathrm{it}}, \mathrm{ToT}_{\mathrm{it}}, \mathrm{OER}_{\mathrm{it}}, \mathrm{e}^{\mathrm{U}_{\mathrm{it}}}\right) \\
& \ln Y_{i t}=\mu+\psi_{1} \operatorname{lnFDI}_{i t}+\psi_{2} \mathrm{IO}_{\mathrm{it}}+\psi_{3} \mathrm{ToT}_{\mathrm{it}}+\psi_{4} \mathrm{OER}_{\mathrm{it}}+\mathrm{U}_{\mathrm{it}} \\
& \mathrm{y}_{\mathrm{it}}=\mu+\psi_{1} \mathrm{x}_{1, \mathrm{it}}+\psi_{2} \mathrm{x}_{2, \mathrm{it}}+\psi_{3} \mathrm{x}_{3, \mathrm{it}}+\psi_{4} \mathrm{x}_{4, \mathrm{it}}+\alpha_{\mathrm{i}}+\varepsilon_{\mathrm{it}}
\end{aligned}
$$

The compact matrix form as

$$
\mathrm{Y}_{\mathrm{it}}=\mu+\psi \mathrm{X}_{\mathrm{it}}^{\prime}+\alpha_{\mathrm{i}}+\varepsilon_{\mathrm{it},} \alpha_{\mathrm{i}} \sim \operatorname{IID}\left(0, \sigma_{\alpha}^{2}\right) \text { and } \varepsilon_{\mathrm{it}} \sim \operatorname{IID}\left(0, \sigma_{\varepsilon}^{2}\right)
$$

where $\mu$ denotes constant intercept, $U_{i t}=\alpha_{i}+\varepsilon_{i t}$ is treated as an error terms which are independently and identically distributed over individuals. It consists of two components: an individual specific component considered as random factors, which does not vary over time or time invariant, while the remain component which is assumed to be uncorrelated over time, where $\psi$ is estimable parameters, $\ln Y_{i t}=y_{i t}, \operatorname{lnFDI}_{i t}=x_{1, i t}$, $\mathrm{IO}_{\text {it }}=\mathrm{x}_{2, \mathrm{it}}, \mathrm{ToT}_{\mathrm{it}}=\mathrm{x}_{3, \mathrm{it}}$, and $\mathrm{OER}_{\mathrm{it}}=\mathrm{x}_{4, \mathrm{it}}$ denote real GDP in logarithm form, foreign direct investment in (log) form, index of openness, terms of trade and official exchange rates, respectively and $\mathrm{i}$ and $\mathrm{t}$ denotes individual country and time variant. 
Autoregressively distributed lag ARDL model has gained popularity as a method of examining in the long run in which cointegrating relationships among the variables exist. It has been given as ARDL $\left(p, q_{1}, \ldots, q_{k}\right)$ where $\mathrm{p}$ is the number of lags of the dependent variable, $\mathrm{q}_{1}$ is the number of lags of the first explanatory variable, and $\mathrm{q}_{\mathrm{k}}$ is the number of lags of the $\mathrm{k}^{\text {th }}$ explanatory variable (Pesaran, Shin, \& Smith, 1999). Thus we can rewrite (3.2.3) in dynamic panel autoregressively distributed lag models ARDL as

$$
\begin{gathered}
y_{i t}=\eta+\prod_{0} y_{i t-1}+\prod_{1} x_{1, i t-1}+\prod_{2} x_{2, i t-1}+\prod_{3} x_{3, i t-1}+\prod_{4} x_{4, i t-1} \\
+\sum_{j=1}^{p-1} \prod_{o j} \Delta y_{i, t-j}+\sum_{j=1}^{q_{1}-1} \prod_{1 j} \Delta x_{1, i, t-j}+\sum_{j=1}^{q_{2}-1} \prod_{2 j} \Delta x_{2, i, t-j}+\sum_{j=1}^{q_{3}-1} \prod_{3 j} \Delta x_{3, i, t-j}+\sum_{j=1}^{q_{4}-1} \prod_{4 j} \Delta x_{4, i, t-j} \\
+\lambda E C T_{i t-1}+\varepsilon_{i t}
\end{gathered}
$$

where $\eta$ is constant intercept, $\Delta$ is the first-difference operator, $\prod_{0}, \ldots, \prod_{4}$ indicate long-run coefficients, $\prod_{0 j}, \ldots, \prod_{4 j}$ denote short-run coefficients, $E C T_{i t-1}$ and $\varepsilon_{i t}$ represent the correction error terms and the independently identically distributed iid terms, respectively.

Using the cointegrating relationship form in equation (4), Pesaran, Shin, and Smith (2001) describe a kind of methodology to test whether ARDL model contains long-run relationship between dependent and the regressors variables. Model selection procedures are available for determining the lag lengths ARDL model. Since ARDL model can be estimated by applying the least squares regression, standard Akaike, Schwarz and Hannan-Quinn information criteria are used for model selection. ARDL model estimates the dynamic relationship between dependent variable and explanatory variables in the short run.

In the cointegration methodology, Johansen $(1991 ; 1995)$ uses single equation methods such as fully modified OLS and dynamic OLS either require all variables to be integrated order one I(1) or require prior knowledge and specification of which variables are integrated order of zero I(0). To alleviate this problem, Pesaran, Shin, and Smith (1999) use the cointegrating systems that can be estimated using ARDL models, with the variables in the cointegrating relationship that can be either $\mathrm{I}(0)$ or I(1), without pre-specifying for the integrated order of I(0) or I(1). The study of Haug (2002) explains that ARDL bounds testing approach is more suitable which provides better results for small sample size and the short- and long-run parameters are estimated simultaneously.

The vector autoregressive VAR is commonly used for estimating and forecasting systems of interrelated time series. It is also used for analyzing the dynamic impact of random disturbances of the variables on the system. The importance of time scale in a VAR methodology, wavelet analyses are desirable local orthonormal bases consisting of small waves that dissect a function into layers of different scale (Schleicher, 2002). The segmentation of time series into different layers makes a very powerful wavelet analysis in the short-, medium-, and long-run time horizons. Nowadays, it has become popular and increasingly used in economic literature (see Gallegati et al., 2015; Reboredo \& Rivera-Castro, 2014; Hacker, Karlsson, \& Månsson, 2012; Almasri \& Shukur, 2003; Ramsey \& Lampart, 1998).

The maximal overlap discrete wavelet decomposition MODWT in the methodology we use in this study allows for moving averages at every scale level and avoids the problems of calculating the moving averages consistently throughout the series by reusing observations in a circular loop. The last value of the original series is simply the first value of that series (Hacker et al., 2012).

Suppose that real GDP, FDI and other explanatory variables for 11 East African countries over the period of 1970-2015 are jointly determined by a VAR system from equation (4) as 


$$
\begin{gathered}
y_{i t}^{D_{j, t}}=\Gamma_{0}+\sum_{k=1}^{K} \Gamma_{10}^{(k)} y_{i, t-k}^{D_{j, t}}+\sum_{k=1}^{K} \Gamma_{11}^{(k)} x_{1 i, t-k}^{D_{j, t}}+\sum_{k=1}^{K} \Gamma_{21}^{(k)} x_{2 i, t-k}^{D_{j, t}} \\
+\sum_{k=1}^{K} \Gamma_{31}^{(k)} x_{3 i, t-k}^{D_{j, t}}+\sum_{k=1}^{K} \Gamma_{41}^{(k)} x_{4 i, t-k}^{D_{j, t}}+\varepsilon_{i t}
\end{gathered}
$$

where $\mathrm{D}$ stands for the differences, $\mathrm{K}$ for the number of lag length, $\mathrm{i}$ for the cross sectional dimension, and $\mathrm{t}$ for time dimension, respectively. $\mathrm{j}=1, \ldots, \mathrm{T}$ denotes time scale decomposition into different layers of the entire panel datasets.

\section{Discussions and Empirical Findings}

\section{Autoregressive Distributive Lags}

We need the specification of optimal lag length for the ARDL models considering lags of the dependent variable as autoregressive and of the independent variables as distributed lags in the regressors. To test for the cointegration, it must be specified how many lags to be included in the model. It has been shown the determination of lag order for the vector autoregressive VAR model with integrated order one I(1) variables. The order of the corresponding vector error correction model VECM is always one less than the VAR because VECM makes adjustment automatically. So we always refer to the order of the underlying VAR (see Tsay, 1984; Paulsen, 1984; Nielsen, 2001). The optimal number of lags for the regression models can be decided by using information criteria AIC (Akaike, 1971), information criteria SBIC (Schwartz, 1978), and information criteria HQIC (Hannan \& Quinn, 1979) and others. These are often used to choose the optimal lag length distributed lag models to compute the log-likelihood function (Johansen, 1988; 1991; 1995).

It has been assumed that all the undertaken variables are integrated order of one, I(1). Then we can develop the standard ARDL model based on equation (4), by using the chosen optimal lag length. In order to determine the optimum lag-length, we take up to 20 lags. Thus, according to the criteria of final prediction error FPE, AIC, SBIC, and HQIC in each test at the $5 \%$ level of significance is reported in Table 1 . These indicate that the optimum lag-length is one because each criterion assumes the lowest points are chosen as an appropriate lag-length.

Table 1

\begin{tabular}{|c|c|c|c|c|c|}
\hline Lag & $\log L$ & FPE & AIC & SBIC & HQIC \\
\hline 0 & $-3,355.81$ & 0.4068 & 24.803 & 24.869 & 24.829 \\
\hline 1 & $-1,692.79$ & $0.2288^{*}$ & $12.714^{*}$ & $13.113^{*}$ & $12.874^{*}$ \\
\hline 2 & $-1,669.09$ & 0.2310 & 12.724 & 13.455 & 13.017 \\
\hline $\begin{array}{l}\cdot \\
. \\
.\end{array}$ & & & & & \\
\hline 20 & $-1,302.25$ & 0.5152 & 13.338 & 20.050 & 16.034 \\
\hline
\end{tabular}

Optimum Lag-Length Selection

Notes. * indicates lag order selected by the criterion in the VAR lag order selection criteria; Endogenous variables: lnGDP, lnFDI, TOT, IO, and OER for the sample period 1970-2015 and the included observations are 271.

\section{Test of Cointegration for Individual and Panel Countries}

After determining the optimum lag-length, we look for cointegration test. In the process of cointegration 
test, first we observe the trace and maximum eigenvalues tests both indicate that there are two panel cointegrating equations at the 5\% level of significance for 11 countries. Then we conduct test for individual countries in which eight out of 11 countries, each shows there is cointegration in the variables. Finally, by excluding countries which do not have cointegration such as Madagascar, Malawi, and Seychelles, the panel cointegration results are reported in Table 2.

The analyses of long-run cointegrating relationships have received remarkable attention in various methods. These methods include dynamic OLS estimation of Pablo (2010), panel fully modified OLS estimators of Phillips and Moon (1999; 2000), Kao and Chiang(2000), panel vector error correction models of Anderson, Qian, and Rasch (2006), fully modified OLS estimators of Pedroni (2000) and Mark and Sul (2003), and the determinants of economic growth for cross-country of Barro (1998). The resultant estimated coefficients obtained by these methods are asymptotically unbiased and normally distributed. We mean cointegration refers to the condition when linear combinations of nonstationary time series are stationary which suggests that there is an existence of long-run equilibrium between the undertaken variables.

Table 2

Test for Panel Cointegration (Unrestricted Cointegration Rank Test)

\begin{tabular}{|c|c|c|c|c|c|c|c|}
\hline \multirow{2}{*}{$\begin{array}{l}\text { Hypothesized } \\
\text { No. of CE(s) }\end{array}$} & \multirow{2}{*}{ Eigenvalue } & \multicolumn{3}{|c|}{ Trace test } & \multicolumn{3}{|c|}{ Maximum eigenvalue test } \\
\hline & & Statistic & $C$ value & $P$ value & Statistic & $C$ value & $P$ value \\
\hline None & 0.1356 & 99.189 & 69.819 & $0.0000 *$ & 49.681 & 33.877 & $0.0003 *$ \\
\hline At most 1 & 0.0776 & 49.508 & 47.856 & $0.0347 *$ & 27.581 & 27.584 & 0.0500 \\
\hline At most 2 & 0.0318 & 21.926 & 29.797 & 0.3026 & 11.004 & 21.132 & 0.6470 \\
\hline At most 3 & 0.0251 & 10.923 & 15.495 & 0.2163 & 8.6810 & 14.265 & 0.3137 \\
\hline At most 4 & 0.0065 & 2.2416 & 3.8415 & 0.1343 & 2.2416 & 3.8415 & 0.1343 \\
\hline
\end{tabular}

Notes. ${ }^{*}$ Denotes rejection of the hypothesis at the 0.05 level and ** MacKinnon-Haug-Michelis (1999) $p$-values. According to Johansen and Juselius (1990), the trace and maximum eigenvalues statistics are calculated as $\lambda_{\operatorname{Tr}}(\mathrm{r})=-\mathrm{T} \sum_{\mathrm{i}=\mathrm{r}+1}^{\mathrm{n}} \ln \left(1-\lambda_{\mathrm{i}}\right)$ and $\lambda_{\max }(r, r+1)=-T \log \left(1-\lambda_{T+1}\right)$, where $n$ is the number of variables in the system for $r=0,1,2, \ldots, n-1$, and $T$ is the sample size and $\lambda$ are the estimates of the eigenvalues, respectively.

We determine number of cointegrating vectors using the trace and the maximum eigenvalues statistics in Johansen's (1991) methodology. In this regard for more specific description, we go back to Johansen and Juselius's (1990) study which advises us the trace statistic tests in the null hypothesis of $r$ cointegrating relations against the alternative of $\mathrm{n}$ cointegrating relations. While the maximum eigenvalue tests in the null hypothesis of $r$ cointegrating relations are against the alternative of $r+1$ cointegrating relations. The tests follow that when the trace and the eigenvalues are all zero, the rank of the matrix will be zero, implying non-cointegration.

We conduct the Johansen test for unrestricted rank and number of cointegrating equations in multivariate analyses. The first column of Table 2 indicates that there are hypothesized number cointegating equations and eigenvalues of the undertaken variables. In the test, we strongly reject the null hypothesis of no cointegration $(r=0)$ against the alternative of one or more cointegrating vectors $(r>0)$ in which at most one is against the alternative. Since the values of trace statistic (0) and (1) exceed their respective critical values at the 5\% significance level, we reject the null hypotheses of zero and at most one cointegrating vectors $(r=0)$ and $(r=1)$ in the trace test and accept the alternative hypotheses of more than zero $(r>0)$ and one cointegrating vectors $(r>$ 1). However, we would reject null hypothesis of no cointegration vector but we would fail to reject the null hypothesis of at most one vector using maximum eigenvalue test. 
On the other hand, the trace statistic (2) and the maximum eigenvalue statistic (1) in the first and second columns of Table 2 are less than their respective critical values at the $5 \%$ significance level, we wouldn't reject the null hypothesis of $r \leq 2$, the cointegrating vectors $(r=2)$ and the null hypothesis of $r \leq 1$ consist of the cointegrating vector $(\mathrm{r}=1)$ respectively. These mean the trace test indicates that there are two cointegrating equations while the maximum eigenvalue test shows that there is one cointegrating equation. Therefore, we conclude that the system has two cointegrating equations because when the trace and the maximum eigenvalue statistics generate different results, we should rely on the value of the trace test (Alexander, 2001). This suggests the Johansen test gives number of cointegration vector which is two within five series. Hence, the variables are integrated of the same order and they move together towards the long-run equilibrium or have long-run relationship.

Since we have dealt with ARDL models, the cointegration tests are not sufficient to prove the existence of long-run relationship among the variables. Thus we need additional one, the bound test.

Table 3

ARDL $(1,1,1,1,1)$ Bound Test for the Existence of Long-Run Relationship

\begin{tabular}{lccc}
\hline & Upper bound values & Wald F-statistic & $P$ value \\
\hline $1 \%$ level of significance & $5 \%$ level of significance & 35.28 & $0.0000^{* *}$
\end{tabular}

Notes. Bounds test for the sets of the null hypothesis: $\mathrm{C}(1)=\mathrm{C}(2)=\mathrm{C}(3)=\mathrm{C}(4)=0$ using the Wald test and $* *$ denotes rejection of the null hypothesis. The upper bound value for each country and the average are 5.06 and 4.01, respectively.

As we can see Table 3, the calculated Wald F-statistic value exceeds the Peasaran upper bound critical value at $1 \%$ and $5 \%$ level of significances; we would reject the null hypothesis of jointly zero. This implies that all variables have long-run association or they move together in the long run and hence, cointegration exists. Since the calculated probability values of $0.23 \%, 2.35 \%$, and $0.25 \%$ all are less than the $5 \%$ level of significance shown in Table 4, we wouldn't reject the null hypothesis of stable and non-autocorrelation or non-serial correlation. Note that individual has the existence of cointegration. Hence, the data are free from the problems of serial auto-correlation of all countries, except Tanzania, now we can estimate the model. The test for stability was done by Magnus and Fosu (2006) prior to our study.

Table 4

Stability Condition and Serial-Autocorrelation Diagnostics

\begin{tabular}{lllll}
\hline \multirow{2}{*}{ Country } & \multicolumn{2}{c}{ Stability Ramsey RESET test } & \multicolumn{2}{c}{ Autocorrelation ML test } \\
\cline { 2 - 5 } & F-statistic value & $P$ value & LM-statistic value & $P$ value \\
\hline Burundi & 0.0113 & 0.9159 & 25.642 & 0.4269 \\
Ethiopia & 0.7028 & 0.4074 & 17.425 & 0.8658 \\
Kenya & 0.0004 & 0.9850 & 21.579 & 0.6599 \\
Mauritius & 0.6764 & 0.4167 & 19.433 & 0.7759 \\
Rwanda & 10.721 & $0.0023^{*}$ & 30.757 & 0.1972 \\
Tanzania & 5.6009 & $0.0235^{*}$ & 49.428 & $0.0025^{*}$ \\
Uganda & 1.7046 & 0.2005 & 32.843 & 0.1350 \\
Zambia & 1.6999 & 0.2005 & 18.077 & 0.8391 \\
\hline
\end{tabular}

Notes. * Denotes rejection of the null hypothesis at the 5\% level of significance. Ramsey RESET is Regression Equation Specification Error Test. The number of fitted terms is one or omitted variables are squares of fitted values. The null hypothesis of Ramsey RESET: stable while that of VEC Residual Serial Correlation of the null hypothesis: No serial correlation at lag-order of one. Test for Autocorrelation LM test uses optimum lag-length of one and Coitegrating Equations of two. 


\section{Parametric Estimations}

Once we conduct the tests for long-run equilibrium relationship, stability condition, and serial-autocorrelation diagnostics for the undertaken variables, our next step will be the estimation of long- and short-run coefficients including the first-order autoregressive coefficient of the error term by using equation (4) and dynamic panel ARDL $(1,1,1,1,1)$ model. Now being based on the cointegrating number of equation which is found to be one, now we can estimate the short-run and the long-run parameters and make use of other analyses.

Table 5

ARDL $(1,1,1,1,1)$ Estimation and Cross-Sectional Dependence Test for Panel Data

\begin{tabular}{|c|c|c|c|}
\hline \multicolumn{4}{|c|}{ Long-run estimation } \\
\hline Variable & Coefficient & t-statistic & $P$ value \\
\hline $\ln \mathrm{FDI}_{\text {it }}$ & 0.1617 & 3.7003 & $0.0003 * *$ \\
\hline TOT $_{\text {it }}$ & 0.4729 & 0.9188 & 0.3590 \\
\hline $\mathrm{IO}_{\mathrm{it}}$ & 2.0492 & 0.3232 & 0.7468 \\
\hline $\mathrm{OER}_{\text {it }}$ & 0.0028 & 4.1433 & $0.0000 * *$ \\
\hline \multicolumn{4}{|c|}{ Short-run estimation } \\
\hline Variable & Coefficient & t-statistic & $P$ value \\
\hline $\mathrm{D}\left(\operatorname{lnFDI} \mathrm{it}_{\mathrm{it}}\right)$ & 0.0006 & 28.498 & $0.0001 * *$ \\
\hline $\mathrm{D}\left(\mathrm{TOT}_{\mathrm{it}}\right)$ & -0.0583 & -16.999 & $0.0004 * *$ \\
\hline $\mathrm{D}\left(\mathrm{IO}_{\mathrm{it}}\right)$ & 0.1153 & 0.9088 & 0.4304 \\
\hline $\mathrm{D}\left(\mathrm{OER}_{\mathrm{it}}\right)$ & -0.0003 & -2875.6 & $0.0000^{* *}$ \\
\hline $\mathrm{ECT}_{\mathrm{i}, \mathrm{t}-1}$ & -0.0584 & -174.24 & $0.0000 * *$ \\
\hline Constant & 0.9029 & 1.3865 & 0.2596 \\
\hline \multicolumn{4}{|c|}{ Cross-sectional dependence test } \\
\hline Type of Test & $\begin{array}{l}\text { Statistic value } \\
\text { ( } p \text { value })\end{array}$ & Type of test & $\begin{array}{l}\text { Statistic value } \\
\text { ( } p \text { value })\end{array}$ \\
\hline Pearson LM & $\begin{array}{l}1.1193 \\
(0.2630)\end{array}$ & Friedman $-\chi^{2}$ & $\begin{array}{l}56.608 \\
(0.0963)\end{array}$ \\
\hline Pearson CD & $\begin{array}{l}2.2972 \\
\left(0.0216^{*}\right) \\
\end{array}$ & Frees normal & $\begin{array}{l}0.0574 \\
(0.5782) \\
\end{array}$ \\
\hline
\end{tabular}

Notes. The partial derivatives $\operatorname{lnGDP}$ with respect to $\operatorname{lnFDI} . \frac{\partial \ln G D P}{\partial \ln \text { FDI }}=\beta_{1} \frac{\text { GDP }}{\text { FDI }}$ which implies $\beta_{1}=\left(\frac{\text { dnGDP }}{\partial \ln \text { FDI }}\right) \cdot\left(\frac{\text { FDI }}{\text { GDP }}\right)$ and the partial derivatives $\operatorname{lnGDP}$ w.r.to $\mathrm{OER}, \frac{\partial \mathrm{GDP}}{\partial \mathrm{OER}}=\beta_{4} \mathrm{GDP}$, which would result in $\beta_{4}=\left(\frac{\partial \mathrm{GDP}}{\partial \mathrm{OER}}\right) \frac{1}{\mathrm{GDP}}$. Dependent variable for the long run and short run are $\operatorname{lnGDP}_{i t}$ and $\mathrm{D}\left(\operatorname{lnGDP}_{\mathrm{it}}\right)$. The $*$ and $* *$ denote rejection the insignificance values for the null hypothesis of cross-section independence at the $1 \%$ and $5 \%$ level of significances. In the cross-sectional dependence, all types of tests indicate there is a cross-sectional independence at the $1 \%$ level of significance. The purpose of logarithmic transforming variables in the model is the common way to handle a non-linear relationship existing between the independent and dependent variables and to capture the outliers.

The panel ARDL $(1,1,1,1,1)$ has been selected from 16 evaluated models in which one is found to be the optimal lag length for dependent and explanatory variables of seven countries, excluding Madagascar, Malawi, Seychelles, and Tanzania. The long-run estimation results reported in Table 5 empirically reveal that there is a significantly positive relationship between the real GDP and the FDI (both in natural logarithm form (ln)). This implies that a $1 \%$ increase in FDL leads to a $0.16 \%$ increase in real GDP for a panel of seven East African countries during the study period. In the meantime, a $1 \%$ increase in the official exchange rate OER leads to a 0 . $28 \%$ increase in real GDP over time. In the short run, the growth rate of FDI has a positive impact whereas of 
terms of trade TOT and OER each of them has a negative impact on the real GDP growth rate for the panel countries. The error correction term which is denoted by $\mathrm{ECT}_{i, t-1}$ for panel countries also reported in Table 5 is negative and significant. It measures the seed of adjustment towards long-run equilibrium, in which the system is getting adjusted towards long-run equilibrium at the seed of 5.8\%. The economy in the panel has a corrected disequilibrium approximately after 17 years, i.e. $1 / 0.0584=17.12$.

\section{Time Scales Wavelet Decompositions}

Finally we investigate the time scale decompositions wavelet analyses using equation (5) to show the inter-temporal causality between FDI and real GDP (in natural logarithms form (ln)) in different time periods. In order to investigate the casual relationship between the real GDP and the FDI in East Africa over the period of 1970-2015, we use heterogeneous panel wavelet analysis of Granger causality test. A multi-resolutionary wavelet decomposition analysis for a maximal overlap discrete wavelet transform MODWT utilizes moving averages of the original data and moving averages of moving averages used for filtering the data. However, using moving averages, the MODWT loses the orthogonality which is the characteristic of basic discrete wavelet transformation (DWT). To maintain consistency in the transformation of the data series, data are considered as a circular loop, with the observation following the last one simply being the first observation (see Hacker et al., 2012). The segmentation of time series into different layers makes use of wavelet analysis become popular in economic analyses in the short-, immediate-, and long-run horizons according to studies by Ramsey and Lampart (1998), Almasri and Shukur (2003), Hacker et al. (2012), and Reboredo and Rivera-Castro (2014).

Table 6

Heterogeneous Panel ARDL $(1,1)$ Time Scale Wavelet Causality Test

\begin{tabular}{lllll}
\hline $\begin{array}{l}\text { Dependent } \\
\text { variable }\end{array}$ & Independent & \multicolumn{3}{c}{ Combined mean coefficients in time scale horizons } \\
\cline { 3 - 4 } variable & $\beta_{1}$ & $\beta_{2}$ & $\beta_{3}$ \\
\hline Real lnGDP & lnFDI & $0.0106\left(37.28^{*}\right)$ & 0.0122 & 0.3584 \\
\multirow{2}{*}{ lnFDI } & \multirow{2}{*}{ Real lnGDP } & 4.9957 & $5.82 *)$ & $\left(54.32^{*}\right)$ \\
& & $(23.64 *)$ & $\left(29.05^{*}\right)$ & 0.4538 \\
\end{tabular}

Notes. Figures in the parenthesis are the calculated $\chi^{2}$ and the $*$ denotes rejection of the null hypothesis of the explanatory that doesn't Granger cause for the dependent variable. The optimal lag length of one in an ARDL method is employed to calculate the probability value for each country. Then we calculate the combined chi-square for the time scale horizons using the formula, $\chi^{2}=-2 \sum_{\mathrm{i}=1}^{\mathrm{L}} \ln \left(\chi_{\mathrm{i}}^{2}\right)$ where $-2 \operatorname{lnp}_{\mathrm{i}}$ has a chi-square distribution and $\mathrm{i}$ stands for country $1,2,3, . ., \mathrm{L}$ (see detailed in Zaykin, Zhivotovsky, Westfall, \& Weir, 2002; Fisher ,1932). We compare these combined $\chi^{2}$ (which is available in Brooks, 2008) with the conventional $\chi^{2}$ of 14.07 at the $5 \%$ level of significance for seven degrees of freedom which represents number of countries.

We use the optimal lag length found to be one in the ARDL method to calculate the probability value for each country. Then we calculate the combined chi-square for the time scale horizons. We also use a simple mean calculation for the combined mean coefficient of the time scale horizons. As it has been shown in Table 6, we use the ARDL $(1,1)$ to determine the wavelet time scaling Granger causality test for a panel of East African economies. The combined mean coefficient values denoted by the time scale by $\beta_{1}, \beta_{2}$, and $\beta_{3}$ represent the short-, medium-, and long-run effects of FDI on GDP and vice versa, respectively. These indicate that there are bi-directional inter-temporal causal relationships between FDI and GDP growth rates.

As you can see the results reported in Table 6, both FDI and GDP cause changes significantly in the short, medium, and long terms. The FDI and GDP growth rate has significantly positive contribution to each other in the short, medium, and long terms in the panel of seven East African countries. As FDI increases by one unit, 
the GDP growth also increases by 0.011 in the short term, 0.022 in the medium, and 0.36 in the long term, in the meantime, as GDP growth increases by one unit, the FDI also increases by $0.499,5.83$, and 0.45 in the short, medium, and long terms, respectively. Moreover, the combined mean coefficients increase over time scaling horizons in general. The calculations are based on the Chlesky variance-response function with the help of standard error in the Monte Carlo simulation.

\section{Conclusion}

We estimate empirically the impact of FDI on real GDP in a panel of seven East African countries for the sample period of 1970-2015. FDI is one of the most dynamic resources flowing into developing countries that can be an important component for economic development, in terms of domestic savings in capital accumulation, employment generation, and growth. It can be also used as a tool for integrating domestic economy into global one, transferring modern technologies, enhancing efficiency, and rising skills of manpower. An increase in FDI may be associated with improved economic growth due to the inflow of capital for the host country which makes a channel into new infrastructure and other projects to boost development. Attracting FDI has assumed a prominent place in the strategies of economic renewal being advocated by policy makers at national, regional, and international levels. The experience of fast-growing East Asian and recently China, has strengthened the belief that attracting FDI is the key to bridging the resource gap in the low-income countries (United Nation, 2005).

We calculate the average when combing mean coefficient of the time scale horizons for the FDI-GDP correlation. The Granger causality test of a panel wavelet analysis in the time scale horizon decompositions is calculated using an ARDL $(1,1)$ method revealing the short-, medium-, and long-term effects of the FDI on GDP and vice versa. These effects show that bi-directional dynamic causal relationships have made the changes to each other. Both FDI and GDP have significantly positive contributions to one another in the short, medium, and long run. Moreover, the combined mean coefficients increase over time in general.

This study contributes to the economic analysis in the long, medium, and short run by applying dynamic causality, designing a new econometric approach (using the time scaling wavelet decomposition in the framework of dynamic panel ARDL). It divides up the time in a more detail way rather than the traditional one. It also brings information within the time range of the impulse and the consequence of the FDI on growth effects. The general objective of this study is to investigate the contribution of FDI to the economic growth in the short, medium, and long term in the trend time horizons in East African economy.

In this study we only focus on the impact of FDI on economic growth of East African region. It may help to provide vital information which serves as a guide for policymakers to deal with. Further studies are required to conduct on this area by considering some approaches which can potentially affect growth such as the impact of corruption, the economic policy in each country, and the interaction among each country when it comes to trade and other factors.

\section{References}

Abala, D. O. (2014). Foreign direct investment and economic growth: An empirical analysis of Kenyan data. DBA Africa Management Review, 4(1), 62-83.

African Economic Research Consortium (AERC). (2006). Foreign direct investment in Sub-Saharan Africa: Origins, targets, impact and potential. African Economic Research Consortium. Nairobi, Kenya.

Akaike, H. (1971). Autoregressive model fitting for control. Annals of the Institute of Statistical Mathematics, 23(1), 163-180. 
Alexander, C (2001). Market models: A guide to financial data analysis. John Wiley \& Sons Ltd.

Alfaro, L., Areendam,R., Chanda, S. K., \& Selin, S. (2000). FDI and economic growth: The role of local financial markets.

Almasri, A., \& Shukur, G. (2003). An illustration of causality relation between government spending and revenue, using wavelet analysis on finnish data. Journal of Applied Statistics, 30(5), 571-584.

Anderson, R., Qian, H., \& Rasch, R. (2006). Analysis of panel vector error correction models using maximum likelihood, the bootstrap and canonical-correlation estimators. Research Division Federal Reserve Bank of St. Louis: Working Paper Series.

Andrew, M. (2000). Trade liberalization and growth: Policy options for African countries in a global economy. Development Bank. Economic Research Papers, No. 60.

Anyanwu, J. C. (2006). Promoting of investment in Africa. African Development Review, 18(1), 42-71.

Anyanwu, J. C. (2012). Why does foreign direct investment go where it goes? New evidence from African countries. Annals of Economics and Finance, 13(2), 425-462.

Anyanwu, J. C., \& Yameogo, N. D. (2013). What drives foreign direct investments into West Africa? An empirical investigation. African Development Bank Tunis, Tunisia.

Baltagi, B. (2005). Econometric analysis of panel data. Chichester: J. Wiley \& Sons.

Basemera, S., Mutenyo, J., Hisali, E., \& Bbaale, E. (2012). Foreign direct investment inflows to East Africa: Do institutions matter? Journal of Business Management and Applied Economics, (5).

Billmeier, A., \& Nannicini, T. (2007). Openness and growth: pursuing empirical glasnost. IMF Working Paper, WP/07/156 Middle East and Central Asia Department Trade.

Booth, D., \& Golooba-Mutebi, F. (2009). Aiding economic growth in Africa: The political economy of roads reform in Uganda. Overseas Development Institute 111 Westminster Bridge Road London SE1 7JD.

Borensztein, E., De Gregorio, J., \& Lee, J. W. (1998). How does foreign direct investment affect economic growth? Journal of International Economics, 45(1), 115-135.

Breitung, J., \&Pesaram, M. H. (2005). Unit roots and Cointegraton in Panels. University of Bonn and Deutsche Bundesbank as well as Cambridge University, respectively.

Brixiova, Z., \& Ndikumana, L. (2011). Supporting Africa's Post-Crisis Growth: The Role of Macroeconomic Policies. African Development Bank, Working Paper Series, No. 254, Tunis, Tunisia.

Brooks, C. (2008). Introductory econometrics for finance (2nd ed.). Cambridge University.

Carkovic, M. V., \& Rosse, L. (2004). Does foreign direct investment accelerate economic growth?

Chirinos-Leañez, A. M., \& Pagliacci, C. (2015). Macroeconomic shocks and the forward yield curve: How important is monetary policy? Macroeconomics and Finance in Emerging Market Economies, 8(3), 201-223.

Cooper, D., \& Dynan, K (2016). Wealth effects and macroeconomic dynamics. Journal of Economic Surveys, 30(1), 34-55. UK: John Wiley \& Sons Ltd.

De Lombaerde, P. A. A. (2009). On the dynamic measurement of economic openness. Journal of Policy Modeling, 31(5), 731-736, Society for Policy Modeling. Elsevier Inc. Science Direct.

De Lombaerde, P., \& Iapadre, P. L. (2008). The world is not flat. implications for the consumption of globalization indicators. World Economics, 9(4), 157-177.

Dupasquier, C., \& Osakwe, P. N. (2006). Foreign direct investment in Africa: Performance, challenges, and responsibilities. Journal of Asian Economics, 17, 241-260.

Economic Commission for Africa Report. (2005). Africa meeting the challenges of unemployment and poverty in Africa.

Edwards, S. (1998). Openness, productivity and growth: What do we really know? The Economic Journal, 108(447), 383-398.

Fisher, R. A. (1932). Statistical methods for research workers. Oliver and Boyd, London.

Frankel, J. A., \& Romer, D. (1999). Does trade cause growth? American Economic Review, 89(3), 379-399.

Frimpong, J. M., \& Oteng-Abayie, E. F. (2006). Bounds testing approach: An examination of foreign direct investment, trade, and growth relationships.

Hacker, R. S., Karlsson, H. K., \& Månsson, K. (2012). The relationship between exchange rates and interest rate differentials: A wavelet approach. The World Economy, 35(9), 1162-1185.

Hailu, D., \& Weeks, J. (2011). Macroeconomic policy for growth and poverty reduction: An application to post-conflict and resource-rich countries. DESA Working Paper No. 108 ST/ESA/2011/DWP/108. Economics and Social Affairs.

Halit, Y. (2003). Trade openness and economic growth: A cross-country empirical investigation. Journal of Development Economics, 72, 57-89. 
Hannan, E. J., \& Quinn, B. G. (1979). The determination of the order of an autoregressive. Journal of the Royal Statistical Society, $41,190-195$.

Haug, A. A. (2002). Temporal aggregation and the power of cointegration tests: A monte carlo study. Oxford Bulletin of Economics and Statistics, 64(4), 399-412.

Johansen, S., \& Juselius, K. (1990). Maximum likelihood estimation and inference on cointegration with application to the demand for money. Oxford Bulletin of Economics and Statistics, 52, 169-210.

Johansen, S. (1988). Statistical analysis of cointegration vectors. Journal of Economic Dynamics and Control, 12(3), 231-254.

Johansen, S. (1991). Estimation and hypothesis testing of cointegration vectors in gaussian vector autoregressive models. Econometrica, 59(6), 1551-1580.

Johansen, S. (1995). Likelihood-based inference in cointegrated vector autoregressive models. New York: Oxford University Press.

Kamaludin, A., Sheikh, Z. Y., \& Mohamed, A. (2013). Feasibility of a monetary union in the East African community: A structural vector autoregression model. Journal of Economics, Business and Management, 1(1).

Kao, C., \& Chiang, M. H. (2000). Estimation and inference of a cointegrated regression in panel data. Nonstationary Panels. Elsevier Science Inc., 15, 179-222.

Kappler, M., Reisen, H., Schularick, M., \& Turkisch, E. (2011). The macroeconomic effects of large exchange rate appreciations. OECD Development Centre Working Paper No. 296.

Koop, G., Leon-Gonzalez, R., \& Strachan, R. (2012). Bayesian model averaging in the instrumental variable regression model. Journal of Econometrics, 171(2), 237-250.

Kotcherlakota, V., \& Sack-Rittenhouse, M. (2000). Index of openness: Measurement and analysis. The Social Science Journal, 37(1), 125-130.

Lane, P. R. (2001). The new open economy macroeconomics: A survey. Journal of International Economics, 54, $235-266$.

Lee, K., Pesaran, M. H., \& Smith, R. (1997). Growth and convergence in a multi-country empirical stochastic solow model. Journal of Appl. Economics, 12(4), 357-392.

Leon-Gonzalez, R., \& Montolio, D. (2012). Endogeneity and panel data in growth regression: A Bayesian model averaging approach. GRIPS Discussion Paper.

Leon-Gonzalez, R., \& Vinayagathasan, T. (2013). Robust determinants of growth in Asian developing economies: A Bayesian panel data model averaging approach. National Graduate Institute for Policy Studies.

Lloyd, P. J., \& MacLaren, D. (2002). Measures of trade openness using CGE analysis. Journal of Policy Modeling, 24(1), 67-81.

Lund, M. T. (2010). Foreign direct investment: Catalyst of economic growth. A dissertation submitted the University of Utah, in Partial Fulfillment for the Requirement for the Degree of Doctor of Philosophy.

Mark, N. C., \& Sul, D. (2003). Cointegration vector estimation by panel DOLS and long-run money demand. Oxford Bulletin of Economics and Statistics, 65(305), 9049.

Michalowski, T. (2012). Foreign direct investment in Sub-Saharan Africa and its effects on economic growth of the region. Working Paper of Uniwersytet Gdañsk, No. 31.

Moral-Benito, E. (2010). Panel growth regressions with general predetermined variables: Likelihood-based estimation and Bayesian averaging. CEMFI Working Papers 1006.

Moral-Benito, E. (2012). Determinants of economic growth: A Bayesian panel data approach. Review of Economics and Statistics, 94, 566-579.

Nachega, J. C., \& Fontaine, T. (2006). Economic growth and total factor productivity in Niger. International Monetary Fund Working Paper, WP/06/208, African Department.

Nellis, J. (2005). Privatization in Africa: What has happened? What is to be done? Centre for Global Development.

Ngeny, K. L., \& Mutuku, C. (2014). Impact of foreign direct investment volatility on economic growth in Kenya. EGARCH Analysis, 3(4), 50-61, Science Publishing Group (http://www.sciencepublishinggroup.com/j/eco). doi: 1 10.11648/j.eco.20140304.11

Nielsen, B. (2001). Order determination in general vector autoregressions. Working Paper, Department of Economics, University of Oxford and Nuffield College.

Noy, I. (2009). The macroeconomic consequences of disasters. Journal of Development Economics, 88, 221-231.

Obstfeld, M., \& Rogoff, K. (1996). Foundations of international macroeconomics. Cambridge, Massachusetts, London, England: MIT Press. 
Obstfeld, M., \& Rogoff, K. (1999). New directions for stochastic open economy models. Journal of International Economics, 50(1), 117-153.

Obstfeld, M. (2001). International macroeconomics: Beyond the mundell-fleming model. Working Paper No. 47, Special Issue, International Monetary Fund.

OECD. (2002). Foreign direct investment for development maximizing benefits, minimizing costs.

Ogalo, V. (2011). Foreign investment in agriculture in Eastern Africa: A general overview of trends and issues.

Oliver, M., \& Andrew, M. (2006). Explaining Africa's export performance-Taking a new look.

Organization for Economic Co-Operation and Development OECD. (2008). Benchmark definition of foreign direct investment (4th ed.).

Pablo, C. (2010). Dynamic OLS estimation of the U.S. Import Demand for Mexican Crude oil. Texas A\&M International University, U.S.

Paulsen, J. (1984). Order determination of multivariate autoregressive time series with unit roots. Journal of Time Series Analysis, 5, 115-127.

Pedroni, P. (2000). Fully modified OLS for heterogeneous cointegrated panels nonstationary panels. Panel Cointegration and Dynamic Panels, 15, 93-130.

Pesaran, M. H., Shin, Y., \& Smith, R. P. (1999). Pooled mean group estimation of dynamic heterogeneous panels. Journal of the American Statistical Association, 94(446), 621-634.

Pesaran, M. H., Shin, Y., \& Smith, R. (2001). Bounds testing approaches to the analysis of level relationships. Journal of Applied Econometrics, 16, 289-326.

Peter, D. (2010). Rethinking the (European) foundations of Sub-Saharan African regional economic integration: A political economy essay. African Economic Outlook, Working Paper No. 293.

Phillips, P. C. B., \& Moon, H. R. (1999). Linear regression limit theory for nonstationary panel data. Econornetrica, forthcoming.

Phillips, P. C. B., \& Moon, H. R. (2000). Cowles foundation for research in economics. Econometric Reviews, 19(3), $263-286$.

Pritchett, L. (1991). Measuring outward-orientation in developing countries: Can it be done? Working Paper No. 566, World Bank, Washington D.C.

Proano, C., Flaschel, P., Ernst, E., \& Semmler, W. (2006). Disequilibrium macroeconomic dynamics, income distribution and wage-price Phillips curves: Evidence from the U.S. and the Euro Area.

Ramsey, J. B., \& Lampart, C. (1998). The decomposition of economic relationships by the time scale using wavelets: Monetary and income. Macroeconomic Dynamics, 2, 49-71.

Resboredo, J. C., \& Rivera-Castro, M. A. (2014). Wavelet-based evidence of the impact of oil price on stock returns. International Review of Economics and Finance, 29, 145-176.

Reinsdorf, M. (2009). Terms of trade effects: Theory and Measurement. Bureau of Economic Analysis.

Reinsdorf, M. (2010). Terms of trade effects: Theory and Measurement. Review of Income and Wealth, 56, 177-205.

Rodriguez, F., \& Rodrik, D. (2001). Trade policy and economic growth: A skeptic's guide to the cross-national evidence. NBER Macroeconomics Annual 2000, 15 Chapter pages in book, 261-338.

Saikonen, P. (1992). Estimation and testing of cointegrating systems by autoregressive approximation. Economic Theory, 8, 1-27.

Sala-i-Martin, X., Doppelhofer, G., \& Miller, R. (2004). Determinants of long-term growth: A Bayesian averaging of classical estimates approach. American Economic Review, 94, 813-835.

Schleicher, C. (2002). An introduction to wavelets for economists. Working Paper 2002-3, Bank of Canada.

Schwartz, B. (1978). Estimating the dimension of a model. The Annals of Statistics, 6(2), 461-464.

Srinivasan, T. N., \& Bhagwati, J. (1999). Outward-orientation and development: Are revisionists right? Mimeo, Yale University.

Sun, X. L. (2002). Foreign direct investment and economic development what do the states need to do? Capacity Development Workshops and Global Forum on Reinventing Government on Globalization, Role of the State and Enabling Environment, Marrakech, Morocco.

Tiziana, F., \& Francesca, M. (2010). The economy of the Italian regions: Recent developments and responses to the economic crisis. European Union Regional Policy, Working Paper, No. 01.

Tsay, R. S. (1984). Order selection in nonstationary autoregressive models. Annals of Statistics, 12, 1425-1433.

Tsikata, T. (2012). The relationship between the foreign exchange regime and macroeconomic performance in Eastern Africa. International Monetary Fund WP/12/148, Working Paper.

UNCTAD. (2010). Foreign direct investment, the transfer and diffusion of technology, and sustainable development.

United Nation. (2005). Economic development in Africa: Rethinking the role of foreign direct investment. New York and Geneva. 
Van der Lugt, S., Hamblin, V., Burgess, M., \& Schickerling, E. (2011). Assessing China's role in foreign direct investment in Southern Africa.

Verbeek, M. (2004). A guide to modern econometrics (2nd ed.). NJ: John Wiley \& Sons, Ltd.

Zaykin, D. V., Zhivotovsky, L. A., Westfall, P. H., \& Weir, B. S. (2002). Truncated product method for combining p-values reference. Genet Epidemiol, 22(2), 170-185. 


\section{Appendices}

\section{Formula and Important Notes}

For an AR $(\rho)$ error specification, the relevant individual cross sectionally CADF statistics are computed from the $\rho$ th order cross-section/time series augmented regression is given as

$\Delta y_{i, t}=\alpha_{i}+\rho_{i} y_{i, t-1}+c_{i} \bar{y}_{t-1}+\sum_{j=1}^{p} d_{i} \Delta \bar{y}_{t-j}+\sum_{j=1}^{p} \beta_{i, j} \Delta y_{i, t-1}+\varepsilon_{i, t}$

where $\varepsilon_{i, t}$ is the idiosyncratic error term, $\bar{y}_{t-1}=\frac{\sum_{i=1}^{N} y_{i, t-1}}{N}$ and $\Delta \bar{y}_{i, t}=\frac{\sum_{i=1}^{N} y_{i, t}}{N}$.

With the transformed data, now we can test for the cross-sectional independence of individual data series (Pesearan, 2007) by constructing a test of the null hypothesis $H_{0}: \rho_{i}$ for all $i$, or the alternative one is $H_{a}: \rho_{i}<0$.

\section{Graph}

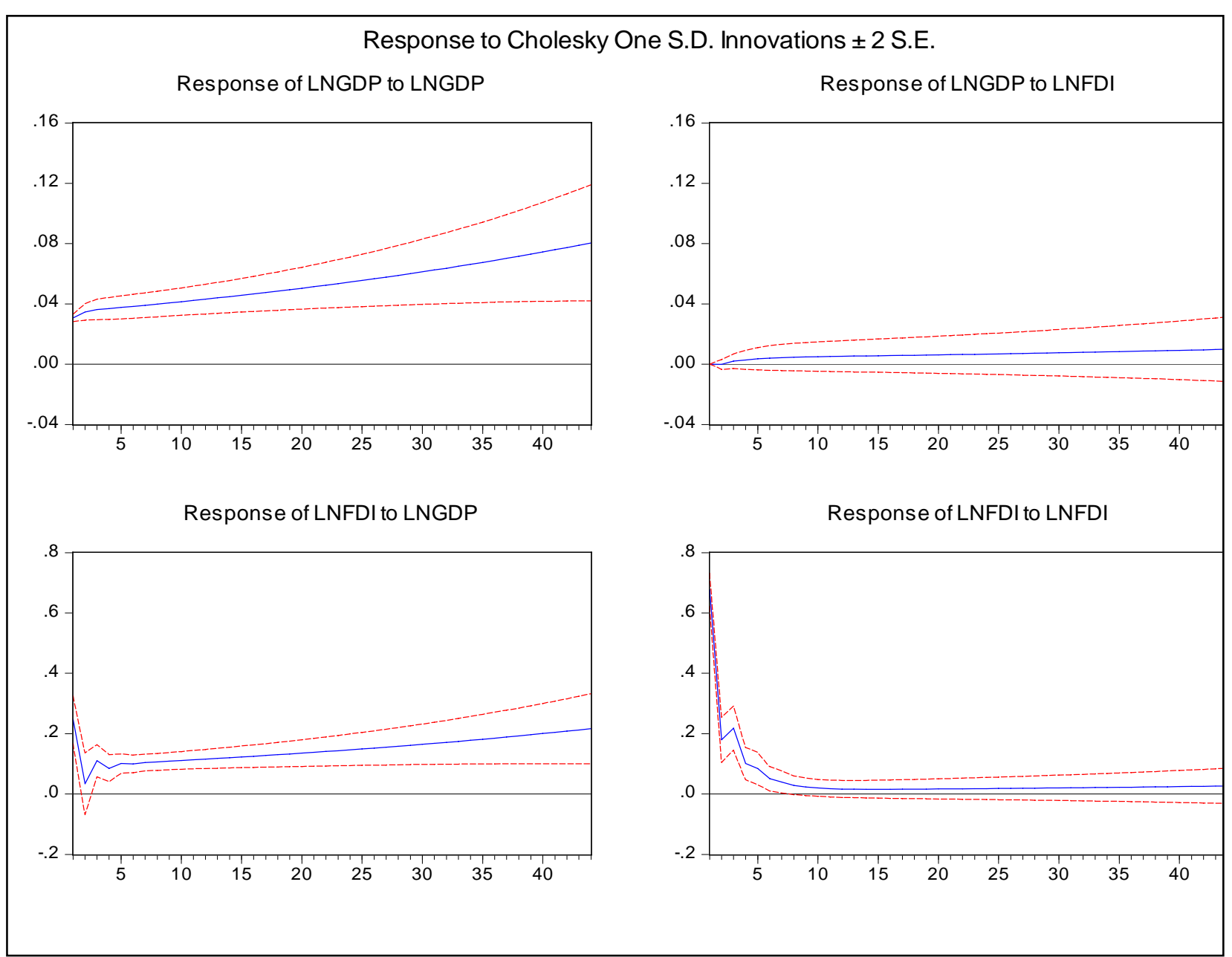

Figure D. Impulse responses combined graphs for real GDP and FDI using Monte Carlo analysis. 